OPEN ACCESS

UWS Academic Portal

\title{
Creating public value through parasport events
}

McPherson, Gayle; Misener, Laura; McGillivray, David; Legg, David

Published in:

Event Management

DOI:

$10.3727 / 152599517 X 14878772869649$

Published: 01/05/2017

Document Version

Peer reviewed version

Link to publication on the UWS Academic Portal

Citation for published version (APA):

McPherson, G., Misener, L., McGillivray, D., \& Legg, D. (2017). Creating public value through parasport events: enabling progressive opportunity . Event Management, 21(2), 185-199.

https://doi.org/10.3727/152599517X14878772869649

\section{General rights}

Copyright and moral rights for the publications made accessible in the UWS Academic Portal are retained by the authors and/or other copyright owners and it is a condition of accessing publications that users recognise and abide by the legal requirements associated with these rights. 


\section{Title}

\section{Creating public value through paras port events: Enabling progressive opportunity}

\section{Abstract}

The hosting of major events presents an opportunity to shape public policy and potentially enable social change. Herein, we discuss two different parasport events, the 2014 Glasgow Commonwealth Games and the 2015 Toronto Pan Am/Parapan American Games that espoused a philosophy of social inclusion and creating social change in sport for persons with disabilities as an outcome of the events. We contend that, as in wider policies for sport, social inclusion has been more illusory than real, sometimes based on increases in facility usage rather than necessarily developing a broader base of participation. Such outcomes stand in contrast to Bozeman and Johnson's (2015) criteria for public value enabling 'progressive opportunity to ensure that members of society have equal access to achieve goals they have set for themselves' (p. 62). We argue that the two parasport events were used by policy makers to demonstrate meaningful avenues to social inclusion, social change and how those in public policy positions have the power to influence and create potential. We examine key policies and policy decision-maker's perspectives, utilising Bozeman's theory on progressive opportunity, regarding the value of two major para sport events in creating social change for persons with disabilities. We conclude that Bozeman's model of progressive opportunity allows for a more sustainable model for bringing the interests of the market and government agencies together to lead to foreseeable and sustainable social change. Notwithstanding, a clear understanding that policy makers need to realise that structural and societal change will not necessarily happen during the lifecycle of Games time. 


\section{Introduction}

The London 2012 Olympic and Paralympic Games were heralded, in the media, as a major breakthrough for raising the profile of disability sport (hereafter parasport) in the United Kingdom (UK) and in changing attitudes towards persons with disabilities ${ }^{1}$ (Penning, 2014). However, since that time others have contested this assertion, commenting that the Games had actually done little to change attitudes towards persons with disabilities (e.g. Walker \& Topping, 2013) and observing the possibility that whatever legacy existed in the short term was "slipping away" (Grey-Thompson, 2013). When governments invest in hosting major sporting events they now, invariably, set out to address social or economic ills, whether in relation to participation in sport or regenerating a particular destination. When hosting parasport events the goal typically includes working towards rectifying the barriers to participation such as accessible facilities and improvements or changes in attitudes towards persons with disabilities. Prior to the 2012 London Olympic Games, Weed and Dowse (2009) warned that in order for successful outcomes to be achieved from hosting a mega sporting event, social legacies need to be planned into the events from the start and not as mere afterthoughts. To achieve social change a long term, sustainable model that includes investment, material policy change and evidence of adding to public value is required. Furthermore, in order to avoid empty rhetoric, assertions about legacy also need to be supported with robust empirical evidence. And yet, to date there has been a paucity of empirical enquiries which seek to assess if there has been a translation between the rhetoric of parasport events and wider social benefits for persons with disabilities. To respond to these questions, we employ the concept of public value to critically assess the value of two major sporting events that include athletes with disabilities (para-athletes). We draw upon a comparative study examining the leveraging potential of parasport events for sustainable

\footnotetext{
1 The authors are aw are of the contested terminology of disability language. We are using the United Nations preferred statement of 'persons with disabilities'.
} 
community participation involving two events: the 2014 Glasgow Commonwealth Games (Scotland) and the 2015 Toronto Parapan American Games (Ontario (ON), Canada). Each of these events had set out a clear public policy agenda of social inclusion and policy change for persons with disabilities. Whilst the wider study has many facets, our empirical focus here is on the policy pronouncements about parasport and the potential public value impact of enabling progressive opportunities made both pre and post- Games. In essence, we seek to add to the wider conversation about whether major (or mega) sporting events can be an effective source of social and public policy change to enhance the lives of marginalised members and communities.

\section{Sport and public policy in the United Kingdom and Canada}

To contextualize our discussion of public value through major sporting events and to help readers better understand how event-led strategies interface with sports policies, we start by outlining the sport policy environment in the United Kingdom (UK) and Canada. We do not attempt to provide an exhaustive overview of each policy context as many others have addressed this task in greater detail (e.g. Barnes, Cousens \& McLean, 2007; Green, 2006; Green \& Houlihan, 2005; Grix \& Carmichael, 2012). Rather our aim is to demonstrate here that public value statements are espoused through the policy context in which sport and events are situated. In particular, over recent decades sport has been viewed as an avenue to achieve other public policy goals, including improved health and wellbeing, crime reduction and the development of social capital.

Until the early 1980s sport policy in both the UK and Canada was primarily justified through an emphasis on sport for all and growing facility provision to increase opportunities for participation. Sport was viewed as a moral good, worthwhile for its own sake and a useful vehicle for the promotion of national pride (Coalter, 1989; Green, 2007). In Canada, 
intervention from the federal government into sport began in the 1960's, evolving throughout the 1970s around a similar Rational Recreation agenda found in the UK (Green, 2007). In the early 1980s, there was a noticeable shift in how sport and recreational opportunities were viewed by an increasingly neoliberalized political elite. In the UK, emerging from a New Right Conservative administration in the late 1970s, sport and recreation moved from being viewed as an investment in recreational welfare (Coalter, 1989) to being only worthy if contributing to the accrual of planned externalities, whether related to health improvement, reductions in crime or economic value. In Canada, during the same period, a differential policy support for sport was evident with changes in federal government responsibilities handing more power to the provinces, albeit framed within the same, increasingly neoliberalized, agenda (Thibault \& Harvey, 2013). The political and economic instability in Canada in the 1990's, in addition to the Ben Johnson doping scandal in 1988, resulted in dramatic shifts in the emphasis on sport provision as funding was cut almost in half during that time (Houlihan, 1997). Unlike in the UK, where sport was increasingly in receipt of public investment on the understanding that it would contribute to wider economic and social externalities, Canadian sport policies at the time emphasised elite sport achievement in the name of national pride and unity above all else.

In both the UK and Canada, through the 1990s and 2000s, policy objectives around sport became more explicitly framed by non-sporting outcomes, including social inclusion, crime reduction, urban regeneration, addressing unhealthy lifestyles, national identity and prestige (Green, 2007). Furthermore, associated with the instrumentalis $\mathrm{m}$ of sport policy during this period, both countries saw increased intervention in elite-level sport, justified on the basis of other externalities, including national prestige, profile on the world stage and civic pride. There was a strong emphasis on elite sport events in Canada in the lead up to hosting both the 1976 Summer Olympic Games in Montreal and the 1988 Winter Olympic 
Games in Calgary, with success on the (home) sporting field viewed as a matter of national importance.

In the UK, the Department of Culture, Media and Sport's (DCMS) White Paper on Sport, Creating a sporting habitfor life drew on the impetus of event hosting as a trigger to support broader sport participation outcomes. There was renewed commitment to ensuring young people had access to participation in sport and recreation and this White Paper set out a vision to achieve a sporting legacy from the 2012 Olympic Games (DCMS, 2012). In Canada, major sporting events were also at the centrepiece of driving the sport policy agenda as the awarding of the rights to Vancouver to host the 2010 Winter Olympic and Paralympic Games signalled a renewed investment in elite sport. The Canadian Sport Policy (2002), focused on securing performance outcomes as a means of triggering broader participation and national pride. It was not until the provincial/territorial meetings for the development of a new Canadian Sport Policy (2012) that a greater emphasis was placed back on broader sporting outcomes including collaboration and linkages with community organisations, service providers and the private sector, and inclusion and accessibility. The Canadian federal government suggested that, "sport is potentially a powerful agent of social change and innovation", going on to highlight commitment to both "increasing participation and excellence in sport" (p. 16, 2012). In each of the cases, it is evident that major sport events have provided catalytic opportunities for the sport policy agenda, especially over the course of the last decade.

However, despite the hope that investments in facilities and associated coaching, sport development and health-related policy interventions would provide equality of opportunity, equality of outcome has remained a forlorn hope. Whilst investment in facilities and sport development capacity in areas of most 'need' has been a feature of major sporting events, this has not addressed the absence of economic, social and cultural capital on the part of some 
citizens necessary to a meaningful sporting and active life. Those with the right forms of capital invariably take up the opportunity to make use of the new facilities and increase their participation, whereas those with barriers to participation remain at the margins. Foley, McGillivray and McPherson (2011), and Misener, McGillivray, McPherson and Legg (2015) have stressed that major sport events and their planned and managed outcomes could present greater opportunities for community participation if managed appropriately. They emphasise the need for ongoing investment in legacy accompanied by systematic evidence of positive impact if these events are to meet the expectations of politicians and the 'trickle down' benefits they piously hoped would emerge, as if by osmosis.

\section{Public value, major sport events and paras port}

When deciding to allocate scarce resources to invest in major sporting events, host governments and their partners are engaged in the practice of public policy making and implementation. Yet, there has been extensive critique in academic circles over the 'value' of these major sporting events in achieving broader economic, social and cultural outcomes (e.g. Adams \& Piekarz, 2015; Pavoni, 2015). Whereas emerging policy debates around participatory democracy promote the role of the public in deciding how public funds are spent, in the context of major sporting events, the extent of citizen involvement in decision making is questioned (Misener \& Mason, 2010). Moreover, there is contestation evident in what public value various stakeholders assign to investment in these events that we believe requires further critical consideration, building on understandings of public value developed in the fields of public administration and new public management.

Firstly, it is important to determine what is meant by public value, how it can be created and how its benefits or impacts can be measured given the proliferation of contributors on the topic (c.f. Alford \& O’Flynn, 2009; Bennington \& Moore, 2011; Bozeman, 2002; Bozeman 
\& Johnson, 2015; Jorgenson \& Bozeman, 2007; Meynhardt, 2009; Porter \& Kramer, 2011; Rhodes \& Wanna, 2007; Stoker, 2006). In definitional terms, public value can be seen simplistically as what is valued by the public or, additionally, what is good for the public (or both) although reaching a consensus on which approach should prevail has proved problematic (Benington \& Moore, 2011; Stoker, 2006). Meynhardt's (2009) work on public value emphasized the role of the public in ensuring policies are fit for purpose for citizens whilst also being influenced by them. He argued that when this is achieved, the public feels a responsibility for helping to successfully implement those public policies. Alford and O'Flynn (2009), meanwhile, suggested that the emphasis on public value is important because of its focus on outcomes that are meaningful for people. Of course, agreement on what public values are shared, how citizens can influence their generation and take ownership of their delivery is difficult to ascertain. Many forms of public value may be contested with competing interests evident. For example, Nabatchi (2012) has argued that public values become real once a consensus has been reached. In contrast, public value failure occurs when either (or both) the market or public sector providing the goods and services fail to deliver. Bozeman (2007) has been a key contributor to the debate on public value. He has argued that a society's "public values are those providing normative consensus about i) the rights, benefits, and prerogatives to which citizens should (and should not) be entitled; the obligations of citizens to society, the state, and one another; and the principles on which governments and policies should be based" (p. 17). The idea of normative consensus is in itself open to interpretation but to take the example of disability rights, enshrined within the UN Convention on the Rights of Persons with Disabilities (2005), there are both legislative expressions (e.g. the UK's Equality Act, 2010 and Canada's Accessibility for Ontarians with Disabilities Act, (AODA), 2005) and policy directives that suggest equitable access to education, work and sport and recreational opportunities are shared public values. Whether 
the rights, benefits and prerogatives contained within the legislative expressions or policy directives lead to the outcomes that Alford and O'Flynn (2009) expect of public value is uncertain, especially when consideration is given to the way persons with disabilities have had to face significant reductions in welfare benefits in Canada and the UK in recent years.

Bozeman and Johnson (2015) have recently argued for two new criteria underpinning public value - 'public sphere' and 'progressive opportunity'. They asserted that "achieving progressive opportunity includes, in most cases, means of redressing structural inequalities" (Bozeman \& Johnson, 2015, p. 62), recognising that not everyone is afforded the same opportunities in life. In this perspective, equality and opportunity are closely aligned (Roemer, 1998). The idea of progressive opportunity is applicable to the field of major sporting events because there remains much debate about whether investments in sporting venues, transport infrastructure and the regeneration of urban locations can effectively address issues relating to issues such as socioeconomic inequality, systemic barriers or poor attitudes towards persons with disabilities. Moreover, some of the principal criticisms of event-led or themed strategies relate to the absence of 'voice' and meaningful opportunities for less influential groups and individuals to shape the outcomes from major sporting events. This is where Bozeman and Johnson's (2015) concept of public sphere is important as they link the achievement of progressive opportunity to a strengthening of the public sphere specifically to the creation of the conditions and mechanisms through which people can communicate effectively about shared values and have these included in the formation of policies and decision making processes. Inequalities and exclusions are likely to be reproduced by major sporting events unless there are clear means through which, for example, persons with disabilities can have their voices heard so that the progressive opportunities available can be realised in practice. 
A cursory glance at the extant literature on major (and mega) sporting events in recent years highlights that they are now seen by local and national political and economic actors as important tools in the delivery of a range of public and social policy objectives (Grix \& Carmichael, 2012; Vanwynsberge, Suborg, \& Wyly, 2013). Major sporting event awarding bodies, including the International Olympic Committee (IOC), Fédération Internationale de Football Association (FIFA) and the Commonwealth Games Federation (CGF) have enshrined the language of legacy within their bidding and delivery processes. Prospective host cities and nations across the world are also developing major sport event strategies designed to attract mobile capital, to help regenerate declining economies and to address the social ills associated with de-industrialisation (Misener \& Mason, 2009). The policy pronouncements that accompany major sporting events are frequently infused with the language of impacts, investments and planned beneficiaries. And yet, there are numerous examples of opposition pertaining to hosting major sporting events that reinforce the notion that public values are not shared by all, or at least there is scepticism about the ability of events to successfully address them (Adams \& Peikarz, 2015; Lenskyj, 2010). For example, residents of Halifax, Nova Scotia, successfully lobbied their city government to withdraw from participation in the bid for the 2014 Commonwealth Games on the basis that welfare spending was much more urgent (Field \& Kidd, 2016).

By linking ideas of public value to major parasport events we can learn from what Bozeman and Johnson (2015) call public policy application. In sum, they assess the fundamental public values held by a particular public policy area and use the technique of public value mapping (Bozeman \& Sarewitz, 2011) to identify public values and track "policy initiatives and outcomes, assessing the relation of these outcomes to the public values given as a starting point" (Johnson \& Bozeman, 2015, p. 63). If we take the example of the relationship between major sport events, parasport governing agencies and policies relating to 
the rights of persons with disabilities in the UK and Canada there is an opportunity to map out the public value discourse surrounding these catalytic moments. This means recognising the value and the limits of the event to produce progressive opportunities.

Within the governance arrangements for major sporting events that include a parasport component (e.g. Paralympic Games, Parapan American Games and the Commonwealth Games) it is anticipated that local and national state actors, alongside sports federations and disability rights organisations can bring pressure to bear on Games organising committees and awarding bodies to ensure that public values associated with the rights of persons with disabilities are enshrined in the planning, delivery and legacy plans for the events themselves. It is within this same framework that pressure for leadership and decision-making is put on National Governing Bodies (NGBs) of sport and international sporting bodies such as the IOC, the International Paralympic Committee (IPC), Commonwealth Games Federation (CGF) and Pan American Sports Organisation (PASO) inter alia, to achieve public value in practice. The early results from the London 2012 Paralympic Games appeared to show evidence of noticeable changes in attitude towards persons with disabilities. However, the fact that reports a year on were less positive highlights the temporal, and possibly ephemeral, nature of the impact of major sporting events on public consciousness. The role of parasport events as a vehicle for delivery of public policy objectives and positive social changes for persons with disabilities is a key theme. Bozeman's criteria for creating public value (2007; 2015) and Meynhardt's (2009) many faces of public value provide a useful platform for analysis of public policy in relation to an examination of social change for increased inclusion through sport for persons with disabilities.

\section{Research Context}


For this study, we examined two major sporting events; the 2014 Glas gow Commonwealth Games (G2014) and the 2015 Toronto ParaPan American Games (TO2015). The former is an integrated event, whereby the parasport medal events are included as part of the overall programme and the latter is separated by time and space (like the Olympic and Paralympic Games). In the case of the Glasgow Commonwealth Games 2014, the policy decision to have a fully inclusive sport programme was taken by the Commonwealth Games Federation and included officially for the first time in Manchester 2002 with 20 countries sending male and female athletes with a disability to compete. The number of medal events has continued to increase each Games with Glasgow 2014 having 22 medal events across five sports and the largest number of athletes. With the increase the number of parasports and para-athletes for these Games, G2014 (Organising Committee) set forth an agenda of social inclusion and awareness of opportunities for persons with disabilities.

The Parapan American Games made its debut in Mexico City in 1999 when 20 countries competed in four sports. In 2007, the Parapan Games were held in Rio de Janeiro alongside the Pan American Games, which is governed by the Pan American Sports Organization (PASO), while the Parapan Am Games are governed by the International Paralympic Committee (IPC). The Toronto PanAm/Parapan American 2015 Games was the first time the two Games were officially held together with one organizing committee and were hailed as a great success with 25 countries participating in 10 sports. The IPC was a key driver of the agenda for accessibility and inclusion in these Games setting forth strict guidelines for sporting venues and the external environment. TO2015 (Organising Committee) sought to go beyond these requirements and influence the wider policy agenda of social inclusion, diversity, and accessibility. The Bid document set out an agenda of inclusion and accessibility for the Games that went well beyond the confines of the event and related infrastructure. 


\section{Research Me thods}

As a result of all the issues just reviewed, understanding the public value accruable from major sporting events specific to persons with disabilities is challenging. This is compounded by what Williams and Hearer (2011) suggest is a shortage of empirical work on public value. We aim to modestly add to the field by examining the policy pronouncements made around two major parasport events, drawing on theories of public value, specifically in relation to progressive opportunity and the public sphere. We do this by analysing policies and key policy decision-makers' perspectives of the value of the two events in progressing a social change agenda for persons with disabilities. This work stems from a larger project examining how large scale parasport events are being leveraged for greater opportunities for community participation for persons with disabilities. As discussed above, the events in question include the 2014 Commonwealth Games held in Glasgow, Scotland; and the 2015 Pan/Parapan American Games hosted in Toronto, Canada. In particular, as our larger project is predicated on a critical disability perspective that emphasises the need to change structural and economic conditions of those with disabilities to increase opportunities, we focus our analysis specifically on Bozeman's notion of progressive opportunity. This idea emphasises the ways in which structural and economic inequalities are addressed through public policy and progressive decision making. In order to do so, we turn to our policy analysis involving government policy documents (federal, provincial and municipal), bid and event related documents, and internal event policy documents around legacy and social inclusion. In total, we examined 42 relevant policy documents including national and local sport policies, strategic planning documents, and Organising Committee (OC) documents (e.g. Bids, Evaluations). The primary purpose of the documents was to frame the context of the interviews, hone the interview guide, and provide the policy backdrop for a broader 
discussion about public value. Second, in the context of these policies, we analysed strategic interviews that were undertaken with key decision makers in senior roles within each Organising Committee (OC), local and provincial government representatives, advisory groups, and event managers for each of the two events. This included 19 interviews for Glasgow 2014 Commonwealth Games and 23 for Toronto 2015 Pan/Parapan American Games between January 2014 and October 2015. The interviews, lasting 30-90 minutes, focused specifically on structural and economic opportunities created through the event and the narratives being formed about the opportunity the event afforded for the creation of public value as per Bozeman's framework. Each member of the research team independently coded the interviews, then one researcher compiled these codes and created meta themes to be shared with everyone. The researchers then reflexively discussed the se themes and worked together to refine those most relevant to the public value perspective and the overall narrative of the project (Kripendorff, 2008). Notably, given the amount of data collected, the researchers discussed at length the selection of themes and quotes to adequately represent the current findings, thus coming to a consensus on how best to present our case. This has meant that we have chosen to use lengthy naturalistic quotes from select individuals as they most accurately represent our findings. Importantly, in line with much of the work on public value, the research team discussed the overall narrative around parasport and disability rights being addressed through the staging of each event. As discussed above, this piece is critical to the framing and creation of progressive opportunity leading to public value and as such the narrative presented below is demonstrative of our findings as related directly to Bozeman's concept of progressive opportunity.

\section{Findings and Discussion}


Our findings reveal the presence of key policy pronouncements at the heart of both Games: inclusion, accessibility and enabling opportunity for structural change. These agenda were not only front and centre of the policy discourse but were utilized to shape key decisions about the event and related activities (e.g. legacy developments). Mirroring Bozeman and Johnson's (2015) analysis of public value, the key policy decisions and narratives around policy objectives provide the potential for normative consensus "rights of entitlement, the obligations of citizens and the principles on which governments and policies should be based" (p. 13). In the case of both Games, public value is expressed through the policy assertions provided by the OC, local and federal government and through the interviews conducted. In the ensuing presentation of the findings, and discussion of their significance, we focus on two main elements of public value as it relates to the potential positive outcomes of major sport events. Firstly, we focus on the potential progressive opportunity available from parasport events and its limits, and secondly, we concentrate on the role of parasport events in providing a place for persons with disabilities to secure a greater space for dialogue and debate in the public sphere of social inclusion and accessibility.

\section{Enabling progressive opportunity}

The ambition to make a meaningful difference to the lives of persons with disabilities through the vehicle of a major sporting event was certainly evident in both the Glasgow Commonwealth Games and the Parapan Am Games, both in terms of strategic and operational planning. In Glasgow, the Chief Executive Officer (CEO) of the local organising committee, Glasgow 2014 Ltd, was conscious of providing an environment that would act as a catalyst for change whether in terms of sport venues and the city's physical infrastructure or in promoting positive attitudes towards disability through those in positions of influence. He argued that: 
We follow that accessible and inclusive route. And that's it. One of the things I always say is you include and give access to those you value. So if we're going to preach equality, humanity, destiny ... then how are we doing that. (CEO G2014)

In the Canadian context, the decision to plan both the PanAm and Parapan Am Games in an integrated fashion also provides an indication of progressive opportunity that directly stems from Canada's previous hosting of the Vancouver 2010 Olympic and Paralympic Games. The Toronto 2015 website states, "Planning also includes a commitment to legacy opportunities, elevating the Paralympic Movement both locally and globally, as well as showcasing accessibility" (accessed 19/5/2016). As the Chief Executive Officer (CEO) for TO2015 described, the integrated approach to planning was a key driver to their access and inclusion strategy which emphasised the notion of diversity as the centrepiece:

Whereas VANOC [2010 Olympic and Paralympic Games Organising Committee] chose to be the greenest Games, we chose diversity to be the pillar that would define us....we started with diversity and inclusion. It would be about truly understanding inclusivity. (CEO, TO2015)

From the outset of the TO2015 bid through to the hosting process the focus of the host organizing committee was making 2015 the "People's Games". Senior Vice President (SVP) of Marketing and Revenue for the Games stated:

This whole idea of the people's Games is that they should be very, very accessible. And when we talked about accessibility we really explored that word with people. So on the Para side of things what people articulated is we want these Games to be 
accessible in many ways. We know what all the infrastructure rules and 'regs' and things that are - which is great, but what we want to make sure is these Games are available to all athletes, to all levels of the ability, to anyone that wants to come and see being able to experience it in their own unique way. So that really started to help us think through how we wanted to present the Games to people. (SVP, TO2015)

This emphasis on diversity enabled the OC to push a particular ideology of inclusion that covered all aspects of accessibility and opportunity. It became embedded in the structure and functioning of the organisation as the Games progressed. It enabled the OC to push an agenda of diversity in various aspects of the Games that they saw necessary to redress some of the inequalities present in society. As the Chief Financial Officer (CFO) of TO2015 indicated "it's allowed us to design our capital builds to be all new infrastructure, sport infrastructure to be totally accessible for athletes of all abilities, which I think is probably one of the greatest legacies or certainly the most obvious legacies of these Games." Thus, although they had separate individuals with the organisation that focused on Parapan Am Games, within the OC the strategic approach was integrative in an attempt to redress some of the societal inequalities:

Toronto 2015's goals are: dignified, integrated, equal and accessible. This is essentially the overriding message of everything, every decision whether it's for a venue, external, internal functional area, an awareness raising event, every decision's overriding priority is the same great Games for everyone regardless of whether you're a Parapan athlete or an able-bodied athlete or a spectator that's young or old using a pram or artificial legs. (Accessibility Advisor, TO2015) 
The social legacy...at the level of children and youth [is critical]. So a small but concrete example: a package goes to every elementary school which the Ministry of Education worked on with us, and talks about inclusiveness, understanding Parapan sports, giving them tools to actually level the playing field by teaching kids how to play goalball, for example. (CEO, TO2015)

These examples denote that the event certainly became an enabler of potential opportunity, but the continuation of the opportunities is, legitimately given the governance structure of major sport events, beyond the scope of the Games organizers. The Senior Manager of Parapan Integration of the TO2015 OC summarizes this progressive potential:

I want the possibilities of people to be able to get active to be more widespread. So that it's not just about going to Variety Village and it's not just about going to the Ability Centre or building other [highly accessible] facilities like that. It's about them being able to go to the arena down the street, the community centre and get active. So those would be the things that I would love to see as a result [of hosting the Games]. (Sport Manager Parapan Integration, TO2015)

It is certainly the case that the key decision makers either with the organising committees or from the local state in both events are aware of the potential of event projects to enable progressive opportunities to be realized. It is beyond the purview of the OC to develop programs outside of the event, but by engaging with key partners, there is opportunity to weave the narrative of the event more effectively into the local policy agenda: 
What we've tried to do is use the Games to act as a catalyst on issues as they pertain to diversity, inclusion, accessibility....we've worked very hard to engage community leaders in our work. We need to work to make sure that we are complementing and leveraging [existing] initiatives, which is why the engaging of leaders in the various spaces has been so important. (Lead of Diversity and Inclusion, TO2015)

Because these athletes are coming here makes us think about not only the sports facilities themselves but the accommodation they're going to be staying in, the catering facilities, the transport system. All of that. So the more that we can build in before the Games to make sure that these athletes are able to fully participate, the more these improvements will be sustainable after. We'll try to keep as many of them as we absolutely can. (CWG Lead for Glasgow City Council)

In the Glasgow context, there is evidence that other investments designed to provide greater opportunities for persons with disabilities were successfully obtained directly, or indirectly, because of the Commonwealth Games. These included: 1) investments in an elite parasport facility at Scotland's national sport centre; 2) support for the national disability sport agency to employ regional coordinators to manage pathway development for clubs and individuals looking to participate in sport; and 3) monies to support the extension of training and development for teachers across Scotland in adaptive sport. In Canada since the Games we have witnessed the appointment of Carla Qualtrough, as the Minister for Sport and Persons with Disabilities. A new role in the Canadian Government and a clear indication of a shift in policy to raise the importance of equality and disadvantaged groups. Qualtrough herself a Paralympian and human rights lawyer stresses that we must not only look at accessibility in a new way but we must think in a new way. This appointment reinforces 
Bozeman and Johnson's (2015) argument that having a healthy public sphere, encouraging dialogue is a prerequisite for the achievement of progressive opportunities. The vision to have a more accessible Canada and an accessible Scotland, were key goals of both Games.

The public pronouncements for Toronto 2015 such as during the One-year count down to the Games: "Making the Games accessible by acting as a role model for accessibility at festivals and events" (TO2015, August 2014) are demonstrative of the ways in which a vision of progressive opportunity was being reinforced. Glasgow were keen to demonstrate post Games that they had achieved their policy ambitions stating "An overarching ambition of the Glasgow Commonwealth Games 2014 was to earn the epithet 'the accessible Games"”. This was mirrored at Scottish Government level through the Mobility Access Group and the Glasgow Commonwealth Games 2014 Accessibility reference group that was set up to work with Glasgow 2014 OC. David Grevemberg, the CEO for Glasgow 2014, stated in the policy document 'An accessible transport strategy' for Glasgow 2014 'Ensuring seamless, accessible transport to and from Games venues forms a huge part of the spectator experience" (Glasgow 2014 Ltd, July 2014). He went on to emphasis the joined up approach with 11 other agencies to developing policy and ensuring accessibility was an inclusive approach.

\section{Disabling progressive opportunity}

Just because equal opportunity is set out as a goal of public policy it does not mean that this is achieved in practice, particularly given the temporal limitations of an event. As Bozeman and Johnson (2015) suggest, "some interests, groups of persons, and individuals have a long historical legacy of disadvantage...that impede their ability to take advantage of "equal opportunity" in the same ways or to the extent of individuals who do not have this legacy of disadvantage." (p. 73). It is fair to suggest that persons with disabilities qualify as 
one group (albeit not an homogenous one) that has experienced a long historical legacy of disadvantage. Whilst the rhetoric emanating from G2015 and TO2015 alongside their partners is strong on enabling equal opportunity, inclusion and diversity, we also need to remember that "there is no equal opportunity when members of society have remarkably different levels of resources available for the exploitation of opportunity" (Bozeman \& Johnson, 2015, p. 74). If major sporting events are to help enshrine public value via progressive opportunity then they need to go beyond the temporal limitations of their existence (in terms of the Games-time experience) to initiate or concretise material improvements in the daily lives of persons with disabilities.

Whilst we have already highlighted how the rhetoric of inclusion and diversity was evident in the official texts of the OCs and host governments, there is also evidence that these discourses were not necessarily translated, or operationalised effectively at the level of practice in both Games settings. In Toronto, the OC failed to see the need to integrate policy drivers and decisions initially in the process. According to TO2015 CEO, his Games had three times the number of venues than the Vancouver Winter Olympic and Paralympic Games did, double the number of athletes, and double the number of sports. At the same time Vancouver 2010 had 4,300 paid staff at Games time while TO2015 had 1,033. So with less staff and a larger Games the need for integrative planning was paramount. With a relatively small OC for TO2015, ensuring seamless integration of the diversity concept throughout the Games was critical. Whilst the small size presented an opportunity to discuss policy issues related to inclusion and diversity relating to persons with disabilities, clear internal structural constraints may have prevented these opportunities from being acted upon early on in the planning process. First, there were only three managers, including only one senior level manager, responsible for the Parapan elements of the Games. Second, the internal policy 
tools enabling inclusion and diversity were developed late in the planning process and only because of a key champion from inside the OC:

One of my first questions was where's the Host City Agreement between Toronto 2015 and the Parapan side, the IPC, because the America's Paralympic Committee is just a working committee of the IPC. So the legal entity that we had to deal with was the IPC and I was told quite early that we didn't need one because the Host City Agreement that we had in place with PASO dealt with any issues, and if you went and read the Host City Agreement for the Pan Am Games there was about three lines in it dealing with the Parapan Am Games. (TO2015 Sport Manager)

The Bid for the PanAm/Parapan Am Games centred upon a vision of integration and social inclusion that failed to follow through in the initial implementation phases. From the outset, the vision of the Games as an integrated event suffered from a failure to be attentive the specific needs of a marginalized group. As Bozeman and Johnson (2015) discuss, equality of opportunity needs to consider the historical trajectory of marginalization where in the past Games the parasport elements have been marginal. Thus, at that point in time, despite recognition that the Parapan Games were smaller in size and scale, in order to rectify the marginalization of opportunity, a policy correction was needed: "my first task was to do a course correction and say if our vision is to have an integrated approach then we have to have equitable treatment of each...so we reached out to the IPC to put into place a framework for a Host City Agreement on Paras" (TO2015 Sport Manager). This put the Parapans a good year behind in terms of planning which was a sign of the lack of foresight from the OC regarding the importance of this policy mechanism in solidifying their stated objective of diversity. While the initial policy problem was rectified, there was a clear inattentiveness to the needs 
of structural changes to enable progressive opportunity at a wider level. It took another several months beyond this agreement for the senior staff on the $\mathrm{OC}$ to agree to elevate the Parapan Integration Manager to the Executive level in the OC and full year beyond that to appoint an Accessibility Advisor with expertise in AODA policy, to help ensure the progressive opportunity voice was at the decision making table.

We also found a paucity of clear resourced investments that enable persons with disabilities to take advantage of, or exploit, the 'opportunities' presented to them by the parasport event in Toronto and the 2014 Glasgow Commonwealth Games. Games-related prioritization of spending on venues, arterial routes and hotel accommodation do little for the progressive opportunity discussed previously. For example, in the Toronto case, the OC undertook facility audits to ensure that venues being used for the Games would meet not only Games standards but offer sustainable accessible service standards to meet AODA requirements. However, few facility managers took the opportunity to make sustainable changes.

It's a very different thing, to be blunt, to put your money where your mouth is and to actually commit funding, resources, people's time and all of those things to make it happen. And to be fair these partners have much bigger things to do than the Games, few took the opportunity to see the bigger picture (Sport Manager Parapan Integration Manager, TO2015)

Similarly, in Glasgow the paucity of resources to allow volunteers with a disability to become an official 'Clydesider' was evident. Official Clydesider volunteers had to commit to 8 hour shifts and 9 days out of the 23 days available. This was not possible for some and acted as a barrier to applications. Thus, whilst the policy ambition was present (they set a 
$15 \%$ target for volunteers from marginalized groups) if those who are already marginalized cannot realise these opportunities effectively then policy failure is likely (Bozeman, 2007). Glasgow City Council responded to this progressive opportunity by working with a charitable funder, the Big Lottery, to provide resources to create a Host Volunteer Programme that focused on providing volunteer opportunities for marginalized groups:

What emerged was there were probably 3 groups in particular - disabled people, older people and those living in deprived areas of Glasgow city that weren't as well represented as a group in the baseline figures. So that's really where the focus in terms of our priority groups for city volunteers came from. So we're not exclusively recruiting from those communities but what we have tried to do is make links through existing networks and forums to try and prioritize involvement of those groups (Volunteer \& Citizenship Manager, G2014).

The need to deliver a major sport event seamlessly, including the recruitment of the 'right' volunteers can work against wider social outcomes. In fact, the market-oriented structures that major sporting events are tied to could actually work to negate some progressive opportunities. Investment decisions associated with new sporting facilities, transport networks and the like are often made within a market framework, with economic legacies in mind rather than as a mechanism to distribute benefits more widely. Again, as Bozeman and Johnson (2015) stress, "unsurprisingly, those persons with the greatest accumulation of assets valued in market transactions tend to acquire greater societal benefits and leave for others disproportionate societal burdens" (p. 75). One example worthy of attention is the unintended consequence of investments in sporting facilities that lead to marginalizing structures that impact persons with disabilities more than others: 
The other thing we have to be really careful about is things such as pricing structure. Now I'm not asking for concessions for disabled people. I'm asking for a fair pricing structure, across the board that allows kids, adults, whatever, including people with disability the chance to use the facilities. My fear is that they put a price banding on the facilities that can't be sustained and people will say I can't afford that... And it's fine saying we spent 132 million pound on this establishment. But it's not about making money, it's about people first and it's about letting the people use it. (Glasgow Life Sport Development Officer)

What is clear from our study is that place alone is not enough to enable progressive opportunities if the social capabilities and constraints to participation are not addressed (Grey-Thomson, 2013). Even if structural constraints are negotiated through the policy agenda, this does not mean that economic and social constraints will automatically follow suit. Games-related sporting facilities may be accessible but if the associated transport and social support required to get you out of the house and to the facility is not in place, then that opportunity to participate is removed. This is where a more holistic understanding of the policies and practices that exist to facilitate social change through opportunities for participation needs to be foregrounded in policy decisions by those in power and leadership roles. Once the venues are accessible, the routes to the venues need to be also; but this means the right levels of support for clubs at the grassroots levels for sports participation, not only pathway development programmes for those that have the social, cultural and economic capital to access them. The danger is that we mirror that of able bodied sports development programmes of the 1980s and 1990s rather than learn from this and ensure that those with a disability can engage in the first place. With cuts to disability living benefits in the UK the 
policies between access and accessibility are out of alignment. Thus, it may be physically possible to get to the venue, but if the social support diminishes then this affects the sport policy of participation for all.

New or improved sporting facilities, which are inclusive and accessible, become critical in terms of enabling opportunities, "I think there is a real heightened expectation that there will be ongoing regular Para sport programming using both the facilities that were created for the Games as well as additional facilities within the community" (ON Parasport Executive Director (ED)). But the reality is that supplying the revenue resources to program, enable transport and maintain staff training to support adaptive sport is beyond the responsibility of Games organizers. It is often left to financially constrained local governments, charitable and community organizations to take on the responsibility for offering accessible programs in the new venues. This means that often there are unrealistic expectations about what a new elite facility can do for local community:

[The new facilities] allows for the normal weekend warrior like myself to be able to enjoy these facilities for the first time ever and be able to go into a change room and not have to fight the change room if you've got a wheelchair or whatever. Now there's really no excuse or obstacle for folks to be able to participate and partake and that's pretty special I think." (Chief Finance Officer (CFO), TO2015)

Clearly, there is a lack of understanding of the constraints to participation for persons with disabilities where a physically accessible place cannot enable progressive opportunity on its own.

Participation, public sphere and parasport 
Bozeman and Johnson (2015) argued that progressive opportunity and public sphere go hand in hand and that the former is unlikely to be realised without the conditions to enable greater participation in the latter being in place. So, without 'voice', or a way of communicating about shared public values, some citizens are excluded and unable to take advantage of the opportunities that could have availed themselves. As Bozeman and Johnson (2015, p. 77) suggested, "it is not possible to simultaneously exclude and provide enhanced opportunity; the exclusion trumps any other form of opportunity. By the same token, inequality (at some thresholds) and inhibited opportunity almost certainly prove fatal to any attempt to improve the public sphere through more extensive or robust participation". In our study of two major parasport sporting events, there is some evidence that persons with disabilities were given a voice, a method of participating and informing policies about the planning, delivery and legacy of the events. For example, the Glasgow OC included an Accessibility Reference Group, designed to ensure progressive policies on inclusion, diversity and human rights were informing the activities of the $\mathrm{OC}$ and its suppliers. In Canada, the Accessibility Advisory Group worked with the OC through its Lead on Diversity and Inclusion who sat on their board. However, the decision to bid for the Games late meant that they had to focus on achieving a couple of specific areas. When reflecting on this, the former CEO noted that:

If we had to do it all over again we probably would have gone along the lines of the Glasgow model. Because what that forces you to do is you bring all the stakeholders to sit around the table to identify what the social-economic sport infrastructure legacies are going to be, and then that becomes your report card to how you're delivering against those in the years leading up to the Games and then after the Games. And then that report card can always be flashed out to everybody to say this is 
what we said we were going to do and this is how things went. We didn't have that here in Toronto. (former CEO, TO2015)

This does not imply, however, that the Games' partners did not have policy goals, but perhaps this demonstrates the need to create a public voice in policy formation. For example, given the prominence of tourism during the Games, TO2015 developed a policy around lowcost simple changes that businesses could make to make themselves more accessible during the games. Businesses were issued a challenge to complete accessibility changes and in turn would be featured as part of the Games tourism portals. Additionally, a Tourism and Accessibility forum was held for Games partners to showcase opportunities regarding ways to integrate accessibility and inclusion into the tourism sectors related to the Games. However, the event was held only 3-months in advance of the Games, scarcely time to make any sustainable changes and was poorly attended as most tourism operators had already produced their seasonal tourism strategies, Games-related strategies, and were tied by the fiscal constraints so close to the Games (TO2015, Evaluation Report). The accessibility advisory groups in Toronto did meet on a regular basis lending a public voice on Games related issues and made recommendations to the $\mathrm{OC}$ on issues related to employment, volunteering, infrastructure, etc. However, the internal processes of the OC focused on enabling an intersection with the public sphere through some levels of participation:

From an accessibility perspective, our objectives have been around ensuring that we use the games to create opportunities for people with disabilities to gain employment, to gain opportunities in business. So from the various contracts and [Request for Proposals] that we put out, and then in terms of leadership opportunities, we've got something like 8 different advisory councils... On the people with disabilities side we've partnered and engaged with employment service providers who service people 
with disabilities. So for every job posting that goes out they receive those postings first and they're encouraged to send us applicants, clients of theirs who we can interview, who we can add to the pool of candidates for a particular position. (Diversity and Inclusion Manager TO2015)

In this case, there was a clear imperative to not only ensure some level of public participation, but to also work with existing programs and frameworks to leverage progressive opportunities.

In Glasgow there are similar examples of policy objectives and levels of public participation, however these were somewhat problematic in the implementation process. Glasgow the Chair of Mobility and Access Committee Scotland expressed concern throughout the process that their views were not being heard and, as a result, the opportunity presented by the Games to enhance everyday accessibility was being lost, "So I just don't know. I mean the lack of information is worrying. I'm not suggesting that nobody is thinking about it, nobody is doing anything about it, but it's not made publicly available that information". This group expressed concerns about their lack of involvement in the planning process and the lateness in information emerging which was likely to impact the wider legacy ambitions, 'I've personally got my concerns that we're not going to get this legacy at all...I don't think people have thought in terms of legacy in terms of the transport aspects sufficiently" (Chair of Mobility and Access Committee Scotland). The difficulty was with the locus and prominence of this group and the fact that the $\mathrm{OC}$ were not accountable to the group but the OC were satisfied they had already exceeded the IPC guidelines for accessibility.

\section{Conclusions and Implications}


In this paper we have sought to highlight how engagement with the concept of public value and, specifically, the ideas of progressive opportunity and public sphere can contribute to the growing body of knowledge around major sporting events and beneficial outcomes. Drawing on examples from two major sporting events, we have shown that an opportunity exists to pursue a progressive opportunity for persons with disabilities through pursuing interventions that prioritise sustainable long term outcomes to education, transport, facility provision and sport development. However, our study has also found that exploitation of the progressive opportunity can be limited by the pressing, operational imperatives of the event project to the detriment of wider public and social policy potential. There is ample research evidence available to suggest that major sporting events are limited in their ability to bring about and sustain social change. Whilst we recognise that host cities have a responsibility to pursue social goals when the events they host involve significant public investments, our findings also suggest that these goals need to be realistic if they are to be meaningful. Major sporting events that contain parasport components can both accelerate and accentuate beneficial outcomes for persons with disabilities if there is a recognition that durable structural inequalities cannot be alleviated over the course of Games time. By effectively leveraging both governmental resources, there is an opportunity to impact educational curricula and practice, business behaviour, transport policy, public awareness and attitudes.

The two Games used in this paper highlighted a trajectory that is positive, but also a need for the public value of parasport events to be presented in terms that allow for wider debate and dialogue in the public sphere. Sport policy in both Countries is on the cusp of making significant strides towards inclusive and accessible participation for all; but those in policy positions need to be careful not to mirror the rhetoric and practice of able bodied sports administrations with investment focusing first or perhaps only on elite pathway 
development rather than trying to increase access to entry level participation in sport and fitness.

Thus, rather than the neo-liberal market driven agenda based on an economic logic of events and subsequent justifications we have seen to date, Bozeman's progressive opportunity offers an embedded economic model that is inclusive and takes account of wider public and social policies to evaluate outcomes of parasport events. Evidence of shifts in inclusion and accessibility policy at governmental, state and agency levels in response to, or as a result of, both of these Games demonstrate a wider recognition and acceptance of the need to actively redress past structural inequalities towards persons with a disability and inclusion in sport. Meynhardt (2009) suggested that public value needs to characterise the relationship between the individual and society and it is here that the relationship between those in leadership roles in delivering parasport events could have engaged more with those in positions of public policy decision-making (Smith, 2014) and those who represent the voice of those with a disability. If these relationships are strengthened then major sport events with a para-element can be leveraged to create the social change they promise, adding value that is lasting, sustainable and deeper than apparently achievable so far. Thus the debates about public value, showing that creating shared value is best suited to the agenda of parasport events where addressing social inequalities and challenges can come the forefront of broader discussions about inclusion and opportunity, this presents the opportunity in the public sphere for a wider inclusive policy agenda. 


\section{References}

Adams, A., \& Piekarz, M. (2015). Sport events and human rights: positive promotion or negative erosion? Journal of Policy Research in Tourism, Leisure and Events, 7, 220236.

Alford, J. \& O'Flynn, J. (2009). Making sense of public value: Concepts, critiques, and emergent Meanings. International Journal of Public Administration, 32, 171-191.

Benington, J. \& Moore, M.H. (2011). Public value in complex and changing times. In, Public Value: Theory and Practice. London, UK: Palgrave Macmillan.

Bozeman, B. (2002). Public value failure: When efficient markets may not do. Public Administration Review, 62, 145-161.

Bozeman, B. (2007). Public values and public interest. Washington, DC: Georgetown University Press.

Bozeman, B., \& Johnson, J. (2015). The political economy of public values. A case for the public sphere and progressive opportunity. The American Review of Public Administration, 45(1), 61-85.

Bozeman, B., \& Sarewitz, D. (2011). Public value mapping and science policy evaluation. Minerva,49(1), 1-23.

Bretchneider, S., Choic, Y., Nabatchi, T., \& O’Leary, R. (2015). Incentivizing collaboration: An experimental analysis of performance information, public value creation and public values promotion. In J.M. Bryson, B. Crosby and L. Bloombery (Eds.) Creating Public Value in Practice: Advancing the Common Good in a Multi-Sector, Shared-Power, NoOne-Wholly-in Charge World. Boca Raton: CRC Press

Canadian Heritage (2012). Canadian Sport Policy 2012. Ottawa: Government of Canada Canadian Heritage (2002). Canadian Sport Policy 2002. Ottawa: Government of Canada 
Cashman, R. (2003) Impact of the Games on Olympic Host Cities. Barcelona: Centre d'Estudis Olimpics.

Coalter, F. (2014). London 2012 A sustainable sporting legacy. In, A. Vigor and M. Mean, After the Goldrush: A sustainable Olympics for London . London: IPPR and Demos.

Coalter, F. (1989). Leisure policy: an unresolvable dualism?. In Leisure for Leisure (pp. 115129). Palgrave Macmillan UK.

Department of Culture, Media and Sport (2012). Creating a sport habit for life: A new youth sport strategy. London: DCMS/Strategy Unit.

Field, R., \& Kidd, B. (2016). Canada and the Pan-American Games. The International Journal of the History of Sport, 33(1-2), 217-238.

Foley, M., McGillivray, D., \& McPherson, G. (2011). Event policy: From theory to strategy. London: Routledge.

Glasgow 2014 Ltd (2014) Accessible Transport Strategy Glasgow 2014 Ltd

Government of Ontario (2005). Accessibility for Ontarians with Disabilities Act. Toronto: Government of Ontario.

Government of the United Kingdom (2010). Equality act 2010. London: UK Government. Green, M. (2007). Olympic glory or grassroots development?: Sport policy priorities in Australia, Canada and the United Kingdom, 1960-2006. The internationaljournal of the history of sport, 24, 921-953.

Grey-Thompson, T. (2013). The Paralympic legacy is slipping away. Too many disabled people are being abandoned by the system. The Guardian, 9 July 2013.

Grix, J., \& Carmichael, F. (2012). Why do governments invest in elite sport? A polemic. International journal of sport policy and politics, 4(1), 73-90.

Houlihan, B. (1997). Sport, national identity and public policy. Nations and nationalism, 3(1), 113-137. 
Jorgensen, B. \& Bozeman, B. (2007). Public values: An inventory. Administration \& Society, 39, 354-381.

Lenskyj, H. (2010). Olympic power, Olympic politics: Behind the scenes. In, A. Bairner and G. Molnar, The politics of the Olympics, A survey. London: Routledge.

Krippendorff, K. (2008). Towards a radically social constructivism. Constructivist Foundations, 3 (2), 91-94, 102.

Meynhardt, T. (2009). Public value inside: What is public value creation. International Journal of Public Administration, 32, 192-219.

Misener, L., McGillivray, D., McPherson, G., \& Legg, D. (2015). Leveraging parasport events for sustainable community participation: The Glasgow 2014 Commonwealth Games. Annals of Leisure Research, 18(4), 450-469.

Misener, L., \& Mason, D. (2010). Towards a community centred approach to corporate community involvement in the sporting events agenda. Journal of Management \& Organization, 16(04), 495-514.

Misener, L., \& Mason, D. S. (2009). Fostering community development through sporting events strategies: An examination of urban regime perceptions. Journal of Sport Management, 23(6), 770-794.

Nabatchi, T. (2012). Putting the 'public' back in public values research: Designing participation to identity and respond to values. Public Administration Review, 699-708

Pavoni, A. (2015). Resistant legacies. Annals of Leisure Research, 18(4), 470-490.

Penning, M. (2014). Paralympics 'transformed attitudes' towards disabled people BBC. Retrieved from http://www.bbc.co.uk/news/uk-28175349.

Porter, M. \& Kramer, M.R. (2011). Creating shared value. Harvard Business Review, January - February 2011, 62-77. 
Rhodes, R.A.W. \& Wanna, J. (2007). The limits to public value, or rescuing responsible government from the platonic guardians. The Australian Journal of Public Administration, 66, 406-421.

Roemer, J. E. (1998). Theories of distributive justice. Boston: Harvard University Press.

Smith, A. (2014). Leveraging sport mega-events: New model or convenient justification?" Journal of Policy Research in Tourism, Leisure and Events 6(1): 15-30. doi:10.1080/19407963.2013.823976.

Stoker, G. (2006). Public value management: A new narrative for networked governance? The American Review of Public Administration, 36, 41.

Thibault, L. \& Harvey, J. (2013). The evolution of sport policy in Canada. In, L. Thibault and J. Harvey (Eds.), Sport Policy in Canada. Ottawa, ON: University of Ottawa Press.

Toronto 2015 (2015). About us. Retrieved from http://www.toronto2015.org/aboutus/parapan-am-games.

United Nations (2006). Convention on the Rights of Persons with Disabilities. Geneva: United Nations.

Vanwynsberghe, R., Surborg, B., \& Wyly, E. (2013). When the Games Come to Town: Neoliberalism, Mega-Events and Social Inclusion in the Vancouver 2010 Winter Olympic Games. International Journal of Urban and Regional Research, 37(6), 20742093.

Walker, P. \& Topping, A. (2013). Paralympics legacy fails to shift attitudes to disabled people. London: $\mathrm{BBC}$.

Weed, M., \& Dowse, S. (2009). A missed opportunity waiting to happen? The social legacy potential of the London 2012 Paralympic Games. Journal of Policy Research in Tourism, Leisure and Events, 1, 170-174. 
Williams, I., \& Hearer, H. (2011). Appraising public value: Past, Present and Futures,” Public Administration, 89, 1367-1384. 